\title{
Correction to: Family involvement as influencer on family firm's growth
}

\author{
Myriam Cano-Rubio ${ }^{1}$. $\cdot$ Guadalupe Fuentes-Lombardo ${ }^{1}$. \\ Valeriano Sanchez-Famoso ${ }^{2}$
}

Published online: 19 May 2021

(c) Springer Science+Business Media, LLC, part of Springer Nature 2021

\section{Correction to: Journal of International Entrepreneurship https://doi.org/10.1007/s10843-021-00290-y}

The original version of this article unfortunately contained a mistake. Acknowledgements have to be included as follows:

"We highly appreciate the financial support from the Chair of Family Business of the University of Jaén, from MCIU/AEI/FEDER-UE under Grant no. RTI2018-097,579-B-100 and from the UPV/EHU (GIU19/057). We also thank two anonymous reviewers for their helpful comments that greatly improved the manuscript."

The original article has been corrected.

Publisher's Note Springer Nature remains neutral with regard to jurisdictional claims in published maps and institutional affiliations.

The original article can be found online at https://doi.org/10.1007/s10843-021-00290-y.

Myriam Cano-Rubio

mcrubio@ujaen.es

Guadalupe Fuentes-Lombardo

gfuentes@ujaen.es

Valeriano Sanchez-Famoso

valeriano.sanchezfamoso@ehu.eus

1 University of Jaen, Campus Las Lagunillas, s/n. D3-137, 23071 Jaen, Spain

2 University of the Basque Country UPV/EHU, C/ Elcano, 21, E48008 Bilbao, Spain 